\title{
Electoral Control in the Presence of Moral Hazard and Adverse Selection*
}

Luis Gustavo Umeno**

Maurício Soares Bugarin ${ }^{* * *}$

\begin{abstract}
This article studies a two-period game between voters and an elected incumbent where voters care both about controlling incumbent corruption and selecting competent incumbents. If voters' reelection criterion is very demanding, only very competent incumbents will be reelected but corruption will be significant. Conversely, if voters use a softer reelection criterion, corruption may be more controlled but too many incompetent incumbents will be reelected. A trade-off arises in equilibrium between the incentive and the selection motives. The model is extended to include society's risk aversion and shows that the more risk averse, the softer the voters' reelection criterion.
\end{abstract}

Keywords: Electoral Competition, Electoral Control, Moral Hazard, Adverse Selection, Reelection.

JEL Codes: C72, H41, D82.

\footnotetext{
${ }^{*}$ Submitted in May 2006. Revised in May 2008. The authors are indebted to Mirta Bugarin for her suggestions and to Fábio Kanczuk for his comments. They are also grateful to the members of the Study Group on Public Sector Economics of ECO/UnB, to participants at the XXIV Brazilian Meeting of Econometrics and to two anonymous referees who substantially contributed to improving the paper. The authors, however, take full responsibility for any remaining errors or omissions. The opinions expressed herein are those of the authors and do not necessarily reflect the view of the Central Bank of Brazil.

${ }^{* *}$ Central Bank of Brazil and University of Brasília, Brazil. E-mail: luis.umeno@bcb.gov.br

*** Ibmec São Paulo, Brazil. E-mail: bugarin@isp.edu.br
} 
The problem of citizens is to induce politicians to enhance the citizens' welfare rather than to pursue their own objectives in collusion with the bureaucracy or with private interests.

Adam Przeworski, "The State in a Market Economy"

(In Joan Marie Nelson, Transforming Post-Communist Political Economies, National Academy Press, 1997)

\section{Introduction}

Politicians are simultaneously a source of satisfaction and concern for society. They are responsible for decisions that strongly affect our daily lives, such as issues regarding monetary policy, exchange rate policy, public expenditures, social security, health, education, and public safety. In periods of economic growth, we often commend our political leaders and reward them with reelection, whereas in periods of economic recession, we turn against their possible incompetence or corruption. ${ }^{1}$ Regardless of the economic situation, however, society acknowledges that an elected politician may put his own interest above that of society. ${ }^{2}$

Therefore, society has developed several mechanisms for exercising control over the behavior of elected incumbents, such as division of powers, Federal Constitution, and numerous laws enforcing the acceptable behavior (ethics) of a politician. Based on the pioneering work carried out by Downs (1957), a wealthy theoretical literature has arisen on the mechanisms voters use to control politicians' behavior. By employing the Principal-Agent model, the seminal works conducted by Barro (1973) and Ferejohn (1986) characterize reelection as an important tool for controlling the behavior of an elected incumbent. More recently, vote splitting was explored in Fiorina $(1988,1992,1996)$, Alesina and Rosenthal $(1989,1995,1996)$, Chari et al. (1997) and Bugarin (1999, 2002). These studies show that negotiation in the Legislature, which is necessary when a significant share of the legislative seats are taken by the opposition parties, can also be used by voters as an electoral control instrument.

This comprehensive literature, however, focuses on solving the adverse incentive (moral hazard) problem, which comes with the difficulty in controlling the decisions made by the elected politician. More recently, a study has investigated another concern felt by voters: will the elected incumbent be competent? This is related to the adverse selection problem, which is orthogonal to the incentive problem: a politician can be more or less competent in the management of public affairs, regardless of his dedication to produce higher returns for society through

\footnotetext{
${ }^{1}$ See the pioneering study by Kerr (1944) or Kramer (1971).

${ }^{2}$ This is currently known as the Madisonian perspective (Madison, 1788), which underscores the role of the voting mechanism in controlling politicians. According to this perspective, the politician should keep his/her elected tenure for a predefined maximum period of time and only if his/her behavior suits the public interest. In Madison's (1788) words, a government should be "administered by persons holding their offices during pleasure, for a limited period, or during good behavior".
} 
his actions. This literature is quite recent and is based on career-concern articles in industrial organization, such as the seminal paper by Holmström (1982), and is therefore less understood in election models.

A notable exception is the substantial contribution by Rogoff and Sibert (1988) and Rogoff (1990), namely the political budget cycle theory. In these studies, voters are concerned with selecting the most competent politician, but in a context in which the politician cannot directly divert money for his own use. The conclusion of that research is that the incumbent overspends during the campaign in order to signal his administrative competence. As there are only two levels of competence, a separating equilibrium is established, in which, as expected, only competent politicians are reelected, at the cost of voters having to put up with an inflated expenditure policy, thus correcting the major criticism to the previous models of political business cycles (Nordhaus, 1975), which implicitly prompted an irrational behavior from voters. ${ }^{3}$

A more recent model that closely resembles the one used in the present study is developed by (Persson and Tabellini, 2000, chapter 4), where the voters' seek to control the incumbent in a context in which different incumbents have different competences, but in which they can also divert money for their own benefit. Nonetheless, this is a symmetric (dis)information model in which the incumbent himself is unaware of his own competence, just like voters are. This reduces the strategic opportunities of players, since the incumbent will always choose the same action, regardless of his type. In addition, voters are risk-neutral, thus minimizing the concern they could have with replacing a competent incumbent with a less competent one.

The present paper analyzes society's optimal electoral choice in the presence of moral hazard and adverse selection when there is asymmetric information between voters and the elected politician in the sense that the incumbent's competence is his private information. The new model, although more complex, highlights the mutually opposing effects of voters' concerns about control and selection. The major result is that the more demanding voters are, the more effectively the selection problem will be solved, because only very competent incumbents will be reelected. However, voters will lose control over less competent incumbents who, by perceiving that their reelection chance is minimal, will divert the highest possible amounts of public money. Conversely, the less demanding voters are, the more incumbents, even those who are less competent, will be encouraged to divert less public money, lured by the possibility of reelection. In this case, one gains in terms of control but loses in terms of selection, since many incompetent incumbents will be reelected.

This paper also assesses the effect of voters' attitude towards risk, concluding

\footnotetext{
${ }^{3}$ See Ferreira and Bugarin (2006, 2007) for a discussion on these two models and for a careful analysis of the robustness of results obtained by Rogoff (1990) in a Federalist Republic with several levels of government and intergovernmental transfers.
} 
that the more risk-averse the society is, the more prone it will be to reelect a politician who has shown poor public administration ability. This result suggests that the same political party will remain in power when societies are more riskaverse, and symmetrically, that different parties will alternate in power in more risk-prone societies.

The paper is organized as follows. Section 2 builds the basic electoral game between risk-neutral voters and an elected politician. Section 3 provides a careful solution to the game, leading to a perfect Bayesian equilibrium with partial control and selection. Section 4 describes a parameterization of the model and calculates its solution based on data for the Brazilian economy for the year 2004. Section 5 extends the model in order to incorporate voters' risk aversion and provides a numerical solution to the equilibrium, using previously calibrated parameters. Finally, Section 6 concludes.

\section{The Electoral Game}

The model used herein is an extension of the one described in (Persson and Tabellini, 2000, chapter 4). The strategic situation involving an elected politician and his voters is represented by a dynamic two-period game with asymmetric information, with the following time structure. In the first period, the elected politician observes his competence and decides how much to produce in terms of public goods, given a budget constraint. The public good is then produced. Voters observe this production but they lack information about the politician's competence; thereafter, they decide whether to reelect this politician or replace him with another one. If reelected, the politician remains in power for another term of office; otherwise, another politician takes over. In the second period, the incumbent chooses a new amount of public goods that will be provided and the game ends.

In this model, incomplete and asymmetric information is associated with the type of a politician, ex-ante unknown to voters. The type of a politician, his private information, reflects his management ability to turn financial resources into public goods. That ability will be hereafter referred to as "competence". From the voters' standpoint, the competence of any politician, either elected or not, is a random variable $\mu$, assumed to be evenly distributed on the interval $\left[1-\frac{1}{\xi}, 1\right]$. Parameter $\xi$ represents the level of heterogeneity regarding the competence of politicians: the higher the value of $\xi$, the smaller the ex-ante difference in competence among incumbents. ${ }^{4}$ Note that the competence expected from a politician, either elected or not, has an expected value $E[\mu]=1-\frac{1}{2 \xi}$.

Additionally, the politician can divert financial resources from the public budget for personal use. The diversion of public resources, sometimes described in the

\footnotetext{
${ }^{4}$ Note that $\xi$ should be greater than 1 so as to avoid negative values for the competence of an incumbent. In addition, we added the technical hypothesis that $\xi<\frac{3}{2}$. Therefore, $\xi \in\left(1, \frac{3}{2}\right)$.
} 
literature as "political income", can occur under different circumstances, but the overbilling of public works for the benefit of firms closely related to the incumbent is the most widespread instance. Hereafter we use the term diverted resources for all uses of public resources that benefit the incumbent but do not benefit voters.

Therefore, the production of a public good at time $t$ is defined by the following equality, where $\gamma_{t}$ stands for the amount of per capita public good produced at time $t, b$ is the per capita revenue ${ }^{5}$ and $r_{t}$ is the per capita amount of resources diverted at time $t$.

$$
\gamma_{t}=\mu\left(b-r_{t}\right)
$$

Note that a more competent incumbent $(\mu=1)$ administers the public budget without wasting any resources, whereas a less competent one $(\mu<1)$ wastes resources in real terms during the provision of the public good. ${ }^{6}$ Therefore, a competent incumbent is able to produce more public goods than a less competent one using the same amount of available resources, i.e., the resources left after diversion. It should be stressed that the concept of competence used here is broad since a politician who knows how to select a competent aide in each of several areas of public administration will be seen as competent, even if he has limited management abilities in these respective areas.

Despite the discretion with which the incumbent diverts resources, there is a minimum amount of budget funds that cannot be diverted, as they are linked to specific expenditures, such as payment of public servants, constitutional transfers, social security, etc. Thus, we postulate the existence of a diversion limit $r_{\max }$ where $0 \leq r_{t} \leq r_{\max }<b$.

The utility of the incumbent is given by the equation below, where $p_{I}$ is the probability of his being reelected, parameter $\delta \in(0,1)$ corresponds to the intertemporal discount factor, common to voters and politicians, and $R$ represents an exogenous income the politician derives for being in power. More specifically, $R$ reflects the value the incumbent gives to his continuity in office. This is also known in the literature as ego rents, ${ }^{7}$ which are rents not denominated directly in monetary values, but that indicate the incumbent's satisfaction with winning the elections and the prestige with staying in power.

$$
u_{T}=r_{1}+p_{1} \delta\left(r_{2}+R\right)
$$

Similarly, the utility of the politician who takes over in the second period is defined below in case the incumbent is not reelected.

\footnotetext{
${ }^{5}$ In this model, we deal with the hypothesis that voters are homogenous and therefore we can think of per capita revenue $(b)$ as the amount of tax rate over the income of each voter.

${ }^{6}$ The authors thank Mirta Bugarin for her suggestions on modeling competence in this context.

${ }^{7}$ See, for instance, (Persson and Tabellini, 2000, chapter 4).
} 


$$
u_{2}=\delta\left(r_{2}+R\right)
$$

Finally, voters are assumed to be all identical, and the utility at time $t$ of a representative voter is given by the following equation, where $y$ is the voter's real income and parameter $\alpha \geq 0$ represents the value given by the voter to the public good compared to private consumption.

$$
w_{t}=y-b+\alpha \gamma_{t} \quad \text { para } \quad t=1,2
$$

Therefore, the first term, $y-b$, corresponds to the income available for private consumption, whereas the second term, $\gamma_{t}$, corresponds to public good consumption.

Note that there are no savings in the model, so there is no possibility of intertemporal transfer of consumption. In addition, we postulate that the voter discounts the future by using the same discount factor $\delta$ of politicians. The latter hypothesis, however, can be relaxed without loss of generality.

We also introduce two technical hypotheses regarding the relative values of the game parameters. The first one is based on the fact that the public budget is already compromised by expenditures (e.g.: payment of public servants) from which resources cannot be directly diverted. In that case, the diversion opportunities do not account for too large a share of the budget. More precisely, we assume the maximum diversion parameter satisfies the following inequality.

$$
r_{\max }^{2}<\delta\left(\frac{b}{2 \xi}-r_{\max }\right)\left(b-r_{\max }\right)
$$

Note that hypothesis (5) implies, in particular, that $r_{\max }<\frac{b}{2}$.

Moreover, we assume that the personal income (ego rents) $R$ is sufficiently high compared to diversion opportunities. More specifically, we postulate the following condition.

$$
R \geq\left(\frac{1-\delta}{\delta}\right) r_{\max }
$$

Note that, as the intertemporal discount factor $\delta$ is close to 1 , the restriction above does not impose significant loss of generality to the model.

Figure 1 shows the extensive form of the game. At the initial node, nature $(N)$ selects the type $\mu \in\left[1-\frac{1}{\xi}, 1\right]$ of the current incumbent. We present only two representative types: $\mu$ and $\mu^{\prime}$. At node $t_{1}$ the incumbent, in his first term of office, may choose any diversion $r_{1} \in\left[0, r_{\max }\right]$, but, for graphic simplicity, only one generic diversion $r_{1}$ is shown. The dotted curves appearing on the initial node as well as on all remaining decision nodes (except nodes $t_{3}$ and $t_{4}$ ), represent the existence of a continuum of choices. 


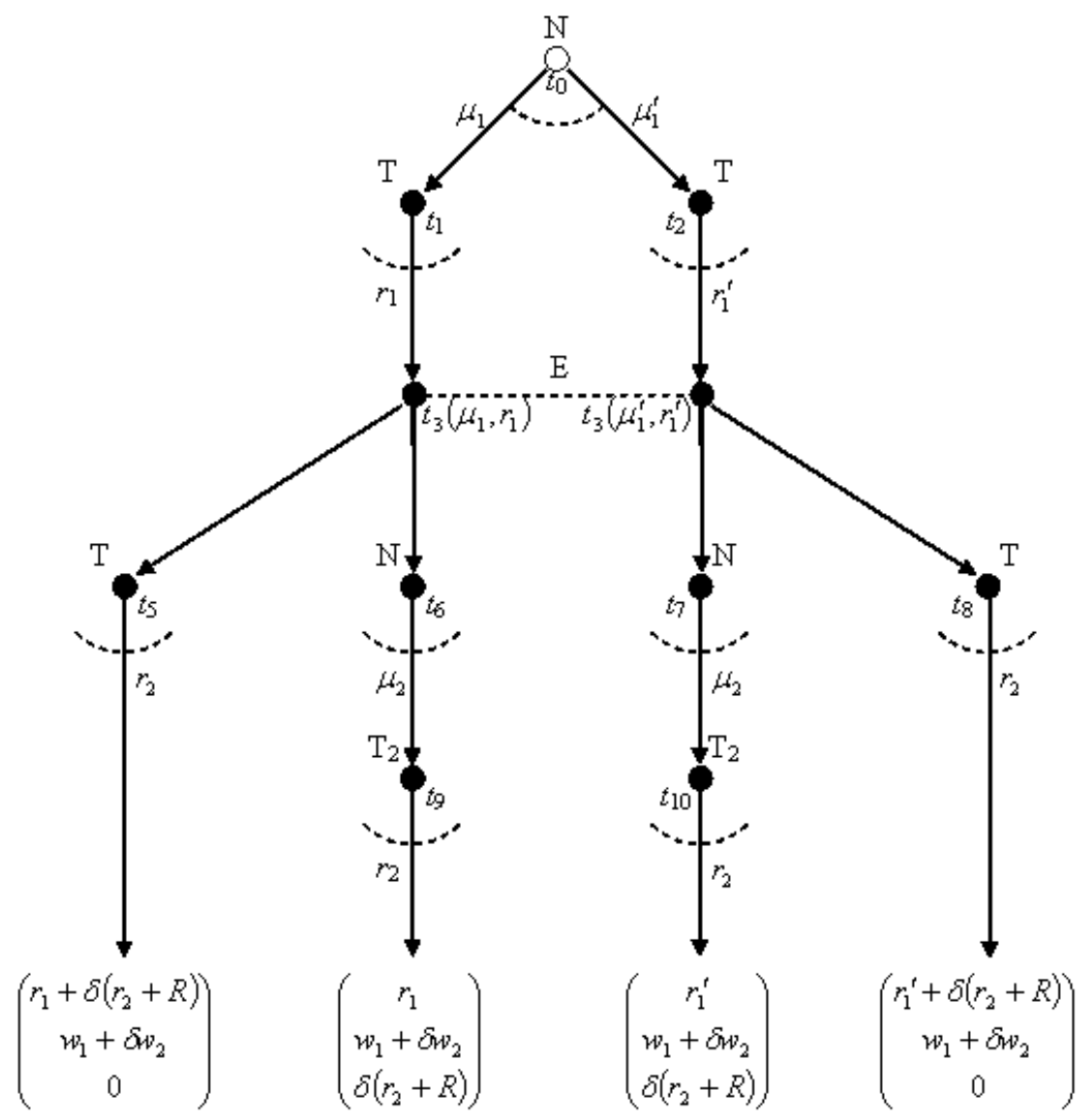

Figure 1

The extensive form electoral game 
The dashed straight line represents the existence of a set of information. Thus, in the information set $\left\{t_{3}=t_{3}\left(\mu_{1}, r_{1}\right), t_{4}=t_{4}\left(\mu_{1}^{\prime}, r_{1}^{\prime}\right)\right\}$ voters observe the final provision of the public good $\gamma_{1}=\mu\left(b r_{1}\right)=\mu^{\prime}\left(b r_{1}^{\prime}\right)$ without knowing whether this corresponds to the selection of diversion $r_{1}$ by an incumbent of type $\mu$ or to the selection of a diversion $r_{1}^{\prime}$ by an incumbent of type $\mu^{\prime}$. Voters $(E)$ then decide to reelect incumbent $(R)$ or not to reelect him $(N R)$. If the incumbent is not reelected, Nature $(N)$ selects competence $\mu_{2}$ of the new incumbent $\left(T_{2}\right)$. In the second period, the elected incumbent ( $T$ in case of reelection, and $T_{2}$ otherwise) selects the level of diversion of public resources $r_{2}$, produces the corresponding amount of public goods, and the game ends. The terminal nodes show the utilities of agents in the following order: incumbent, representative voter and challenger.

\section{Perfect Bayesian Equilibrium}

The game is initially solved by the general concept of backward induction or, more precisely, by sequential rationality, in order to obtain a perfect Bayesian equilibrium.

In the second period, on nodes $t_{5}$ and $t_{8}$, cases in which the incumbent was reelected, the politician's best choice corresponds to diverting the highest possible amount of public resources since the game ends in that period. Therefore, on these nodes, the incumbent will choose $r_{2}=r_{\max }$. For similar reasons, on nodes $t_{9}$ and $t_{10}$, the new incumbent, $T_{2}$, will also choose $r_{2}=r_{\max }$, regardless of the type.

Going up one more level on the extensive form game, the voter must decide whether to reelect or not the incumbent at the information set of type $\left\{t_{3}\left(\mu_{1}, r_{1}\right), t_{4}\left(\mu_{1}^{\prime}, r_{1}^{\prime}\right)\right\}$. As the only information available to voters is about the provision of the public good, $\gamma_{1}$, they must define their reelection criterion based on that observation. So as to reduce as much as possible the diversion of resources in the first period, we look for an equilibrium strategy based on a reelection rule $\Gamma$ of the following type, where $p_{I}$ represents the probability of voters reelecting the incumbent.

$$
\begin{cases}p_{I}=1, & \gamma_{1} \geq \Gamma \\ p_{I}=0, & \gamma_{1}<\Gamma\end{cases}
$$

Therefore, the criterion above determines that the incumbent will be reelected if he manages to provide a minimum amount of public good, $\Gamma$, and that he will not be reelected if the amount of public good is below that level. The optimal choice of $\Gamma$ will be determined later.

The next step in the resolution consists of the incumbent's decision on diverting resources in the first term of office.

Note that, according to (7) and (1), the incumbent will be reelected if and only if $\mu \geq \frac{\gamma}{b-r_{1}}$. The worst incumbent (the least competent) able to be reelected is the one of the type $\mu_{\mathrm{inf}}=\frac{\Gamma}{b}$, i.e., if incumbent $\mu_{\mathrm{inf}}$ does not divert any resource 
$\left(r_{1}=0\right)$, then he will be reelected. Finally, there may be so competent incumbents that $\mu \geq \frac{\Gamma}{b-r_{\max }}$, i.e., even if they divert the highest possible amount of resources, they will still be reelected. We will refer to the worst (least competent) of these more competent incumbents as $^{8} \mu_{\text {sup }}=\frac{\Gamma}{b-r_{\max }}$.

Therefore, we can organize the types of incumbents into three classes, as follows: If $\mu<\mu \mathrm{inf}$, then the incumbent will not be reelected even if he does not divert any resources. Note that in this case, the incumbent's optimal choice in the first period is to divert as many resources as possible, i.e., $r_{1}=r_{\max }$.

If $\mu \in\left[\mu_{\text {inf }}, \mu_{\text {sup }}\right)$, then the incumbent can be reelected if he chooses $r_{1} \leq b-\frac{\Gamma}{\mu}$. In this case, to be reelected, the incumbent's best choice in the first period should be $r_{1}=r_{1}(\mu)=b-\frac{\Gamma}{\mu}$. On the other hand, if the incumbent does not want to be reelected, he should choose $r_{1}=r_{\max }$, the highest possible amount of diversion in the first period.

Finally, if $\mu \geq \mu_{\text {sup }}$, then the incumbent will be reelected regardless of how many resources he diverts. So, the incumbent will choose the maximum diversion $r_{1}=r_{\max }$.

According to the previous analysis, the incumbent might not want to be reelected in the case where $\mu \in\left[\mu_{\text {inf }}, \mu_{\text {sup }}\right)$. This will occur if the incumbent would rather divert the highest amount of resources in the first period and not be reelected than reduce the amount of resources diverted and then be able to divert the highest possible amount of resources in the next period. However, condition (6) guarantees that this will not happen, as described in detail in the Appendix. Therefore, given condition (6), an incumbent with intermediate competence $\mu \in\left[\mu_{\mathrm{inf}}, \mu_{\mathrm{sup}}\right)$ can be controlled by voters, thus reducing diversion in the first period in order to be reelected.

Let us analyze the voters' best response regarding the choice of the reelection criterion $\Gamma^{*}$.

First, consider interval $I(\Gamma)=\left[\mu_{\text {inf }}(\Gamma), \mu_{\text {inf }}(\Gamma), \mu_{\text {sup }}(\Gamma)\right]$. Note that $I(\Gamma)$ is an interval whose length increases linearly with $\Gamma$, with the following property. When $\Gamma=0$, the length of the interval $I$ is zero; as $\Gamma$ increases, the length of this interval also increases and, concomitantly, the interval shifts to the right.

Therefore, we can define five different situations according to the position of $\mu_{\text {sup }}$ and $\mu_{\text {inf }}$ in the support of the distribution of $\mu$, that correspond to five intervals $I(\Gamma)$. For the sake of concision we will analyze only Cases 1, 3 and 5 in detail, and solve for Cases 2 and 4 in the Appendix.

\section{Case 1: Lenient voters}

First assume that $\mu_{\mathrm{inf}}<\mu_{\mathrm{sup}} \leq 1-\frac{1}{\xi}$. In this case, we have $\mu \geq \mu_{\text {sup }}$ for every $\mu \in\left[1-\frac{1}{\xi}, 1\right]$. Therefore, as previously seen, the incumbent will be

\footnotetext{
${ }^{8}$ Note that parameters $\mu_{i n f}$ and $\mu_{\text {sup }}$ depend on the selection of strategy $\Gamma: \mu_{\text {inf }}=\mu_{\text {inf }}(\Gamma)$ and $\mu_{\text {sup }}=\mu_{\text {sup }}(\Gamma)$. The reduced-form notation is used in the text for simplicity.
} 
reelected regardless of the choice of diversion. So, the incumbent will always choose maximum diversion $r_{1}=r_{\max }$ and will be reelected.

Observe that this condition corresponds to $\Gamma \leq\left(1-\frac{1}{\xi}\right)\left(b-r_{\max }\right)$, i.e., the voter is so lenient that all incumbents will always be reelected. ${ }^{9}$ In this case, $\Gamma$ is so small that it will not affect the choice for the incumbent. Figure 2 shows the position of $\mu_{\text {sup }}$, always inferior to any competence on the support of the distribution of $\mu$ for the first case.

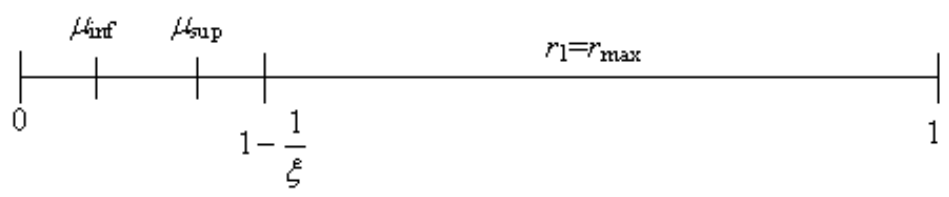

Figure 2

Case 1: Lenient voters

The voters' expected utility in both periods is given by:

$U_{1}=\int_{1-\frac{1}{\xi}}^{1} \mu\left(b-r_{\max }\right) f(\mu) d \mu+\int_{1-\frac{1}{\xi}}^{1} \delta \mu\left(b-r_{\max }\right) f(\mu) d \mu=(1+\delta) \frac{2 \xi-1}{2 \xi}\left(b-r_{\max }\right)$

The first integrand above represents a voter's utility when the incumbent diverts the highest amount of resources in the first term of office. The second term refers to the utility in the second term of office, knowing that the incumbent also diverts the maximum amount of resources in the second period (by sequential rationality) and that the voter discounts the future by $\delta$. Note that the second term in Equation (8) indicates that any choice of $\Gamma$ on this case's interval results in the same utility for the voter.

It should be underscored that in this case where the voter is lenient, there is no electoral control, and then the incumbent can divert as many resources as possible.

\footnotetext{
${ }^{9}$ The interval for $\Gamma$ is derived as follows: $\mu_{\text {sup }} \leq 1-\frac{1}{\xi} \Leftrightarrow \frac{\Gamma}{b-r_{\max }} \leq 1-\frac{1}{\xi} \Leftrightarrow \Gamma \leq$ $\left(1-\frac{1}{\xi}\right)\left(b-r_{\max }\right)$. 


\section{Case 2: Partially demanding voters}

This is the case where $\mu_{\text {sup }}>1-\frac{1}{\xi}$ and $\mu_{\text {inf }} \leq 1-\frac{1}{\xi}$, which corresponds to $\left(1-\frac{1}{\xi}\right)\left(b-r_{\max }\right)<\Gamma \leq\left(1-\frac{1}{\xi}\right) b$. This case is described in detail in the Appendix.

\section{Case 3: Demanding voters}

Suppose now that that $\mu_{\text {inf }}>1-\frac{1}{\xi}$ and $\mu_{\text {sup }} \leq 1$, i.e., $\left(1-\frac{1}{\xi}\right) b<\Gamma \leq b-r_{\max }$. Figure 3 shows the case in which the voter is more demanding, and therefore some types of poorly competent incumbents will not satisfy the condition for reelection, opting for maximum diversion $r_{\max }$ in the first period.

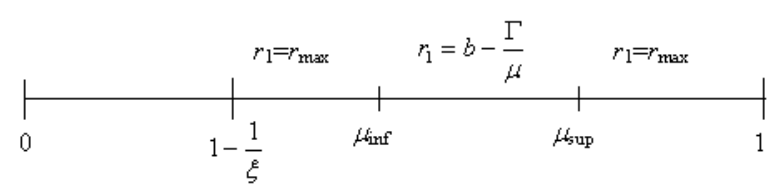

Figure 3

Case 3: Demanding voters

Following the same procedure as in the previous cases, the voter's problem is given by:

$$
\left\{\begin{array}{l}
\max _{\Gamma} \int_{1-\frac{1}{\xi}}^{\mu_{\mathrm{inf}}}\left[\mu\left(b-r_{\max }\right)+\delta E[\mu]\left(b-r_{\max }\right)\right] f(\mu) d \mu \\
+\int_{\mu_{\mathrm{sup}}}^{\mu_{\mathrm{inf}}}\left[\Gamma+\delta \mu\left(b-r_{\max }\right)\right] f(\mu) d \mu \\
+\int^{1}(1+\delta) \mu\left(b-r_{\max }\right) f(\mu) d \mu \\
s . a:\left(1-\frac{1}{\xi}\right) b, \Gamma \leq b-r_{\max }
\end{array}\right.
$$

The first term in the objective function of problem (9) accounts for all the situations in which the incumbent is very incompetent, in whose case he will divert the highest possible amount of resources in the first period and will not be reelected. Therefore, in the second period, another incumbent, with expected competence $E[\mu]$, takes over. The second term corresponds to the situation in which the incumbent can be reelected by producing $\Gamma$. In that case, the voter 
will receive $\Gamma$ in the first period and the incumbent diverts the highest amount of resources in the second period. The third term corresponds to situations in which a very competent incumbent diverts the maximum amount of resources and is nevertheless reelected.

Note that in this case both moral hazard and adverse selection problems are present. In fact, by choosing $\Gamma$, the voter is faced with the following dilemma: a larger $\Gamma$ allow the worst types to be excluded, thus helping to select the best incumbents for the subsequent period (selection). However, voters do not control at all the diversion of public resources by these incompetent incumbents (moral hazard). On the other hand, smaller $\Gamma$ values allow less competent incumbents to be reelected, affecting the capacity to choose the best incumbents (selection), but exercise better control over the diversion by these less competent incumbents who can now meet the reelection criterion (moral hazard). Voters' optimal choice will depend on a balance between these two dilemmas.

By calculating the integral ${ }^{10}$ and then ignoring the restrictions related to the domain of variable $\Gamma$, we obtain the following first-order condition:

$$
\Gamma^{*}=\left(1-\frac{1}{2 \xi}\right) \frac{\delta\left(b-r_{\max }\right)^{2} b}{b\left(b-2 r_{\max }\right)-(1-\delta)\left(b-r_{\max }\right)^{2}}
$$

It is straightforward to check that $\Gamma^{*}>\left(1-\frac{1}{\xi}\right) b$, as described in detail in the Appendix. In addition, the second-order condition for a maximum is satisfied if $\delta>\frac{r_{\max }^{2}}{\left(b-r_{\max }\right)^{2}}=\delta_{1}$, as also shown in detail in the Appendix. Moreover, $\delta_{1}<1$ since $b>2 r_{\max }$.

Thus, if $\delta>\delta_{1}$, then we can assert that either the maximum $\Gamma^{*}$ is an interior solution to problem (9) or the function is increasing throughout the relevant domain and the voters' optimal choice on this interval is its right boundary $\Gamma=b-r_{\max }$. In the Appendix, we show that the necessary and sufficient condition for $\Gamma^{*}$ to be within the interval $\left(\left(1-\frac{1}{\xi}\right) b, b-r_{\max }\right)$ is exactly condition (5). Note that condition (5) stresses the role of diversion opportunities $\left(r_{\max }\right)$ in the existence of an internal solution to Case 3 .

\section{Case 4: Very demanding voters}

This is the case where $1-\frac{1}{\xi} \leq \mu_{\text {inf }}<1$ and $\mu_{\text {sup }}>1$, which corresponds to $b-r_{\max } \leq \Gamma<b$. This case is shown in detail in the Appendix.

\section{Case 5: Extremely demanding voters}

This last case occurs when $\mu_{\mathrm{inf}} \geq 1$ and $\mu_{\text {sup }}>1$, which corresponds to $\Gamma \geq b$. This is a trivial and poorly intuitive situation, in which voters are so demanding

\footnotetext{
${ }^{10}$ The calculation of the integral is shown in the Appendix. The calculation of the first-order condition is then straightforward.
} 
that no incumbent will be able to meet the reelection criterion, even if he does not divert any resource. In that case, the incumbent will choose the maximum diversion in the first period, will not be reelected and the new incumbent in the second period will also choose the maximum diversion. There is neither selection of the most competent incumbent nor control over the incumbent's diversion.

The incumbent's utility in this case is:

$$
(1+\delta) E[\mu]\left(b-r_{\max }\right)=(1+\delta) \frac{2 \xi-1}{2 \xi}\left(b-r_{\max }\right)
$$

Conclusion: Profile of sequentially rational strategies, beliefs, and perfect Bayesian equilibrium

The analysis of Cases 1 and 5 leads to the following conclusions. First, voters' utility varies continually when parameter $\Gamma$ ranges from 0 to infinity, as can be seen in the Appendix. Next, it is constant at its global minimum value $(1+\delta) \frac{2 \xi-1}{2 \xi}\left(b-r_{\max }\right)$ when $\Gamma \leq\left(1-\frac{1}{\xi}\right)\left(b-r_{\max }\right)$ (any incumbent is always reelected regardless of the selected diversion, Case 1) and when $\Gamma \geq b$ (no incumbent is reelected even if no resources are diverted, Case 5). Additionally, based on the continuity of the objective function, the solution to the problem is necessarily within the interval $\left(1-\frac{1}{\xi}\right) b<\Gamma<b-r_{\max }$, corresponding to Case 3. If, additionally, the agents do not discount the future excessively, such that $\delta>\frac{f_{\max }^{2}}{\left(b-r_{\max }\right)^{2}}$, then the voters' optimal choice will be $\bar{\Gamma}=\Gamma^{*}=\frac{\delta\left(b-r_{\max }\right)^{2} b(2 \xi-1)}{2 \xi^{2}\left[b\left(b-2 r_{\max }\right)-(1-\delta)\left(b-r_{\max }\right)^{2}\right]}$.

Next we present the corresponding profile of strategies.

Voters:

(i) Reelect the incumbent if the production of the public good, $\Gamma$, reaches at least the value $\bar{\Gamma}$.

(ii) Do not reelect the incumbent, otherwise.

Incumbent:

(i) Chooses maximum diversion $r_{\max }$ in case of poor competence $\mu<\mu_{\text {inf }}(\bar{\Gamma})$, produces $\Gamma(\mu)=\mu\left(b-r_{\max }\right)<\bar{\Gamma}$ and is not reelected.

(ii) Chooses diversion $r_{1}=b-\frac{\bar{\Gamma}}{\mu}$ in case of intermediate competence $\mu \in$ $\left[\mu_{\text {inf }}(\bar{\Gamma}), \mu_{\text {sup }}(\bar{\Gamma})\right]$, produces exactly the amount $\bar{\Gamma}$ of public good required for reelection and is reelected.

(iii) Chooses maximum diversion $r_{\max }$ in case of high competence $\mu>\mu_{\text {sup }}(\bar{\Gamma})$, produces $\Gamma(\mu)=\mu\left(b-r_{\max }\right)>\bar{\Gamma}$ and is reelected. 
(iv) In the second period, regardless of the type $\mu$ of the incumbent, he will choose maximum diversion $r_{\max }$, therefore producing $\Gamma(\mu)=\mu\left(b-r_{\max }\right)$ units of public good.

It should be highlighted that in this profile voters balance their two concerns - control over diversion and selection of the competent incumbent - by choosing a strategy that disciplines some of the incumbents (those who have enough competence to be reelected, making them reduce diversions in the first period in case of intermediate competence), and that does not reelect incumbents with poor competence.

To conclude the construction of the equilibrium it is necessary to check the Bayesian consistency of this profile of strategies. Therefore, consider the following system of beliefs.

(i) If the incumbent produces an amount of public good that is lower than $\bar{\Gamma}$, then voters believe that the incumbent is poorly competent: $\mu<\mu_{\text {inf }}(\bar{\Gamma})$, being evenly distributed on the interval $\left[1-\frac{1}{\xi}, \mu_{\text {inf }}(\bar{\Gamma})\right]$.

(ii) If the incumbent produces the exact amount $\bar{\Gamma}$ of public good, then voters estimate that the incumbent has an intermediate level of competence: $\mu \in$ $\left[\mu_{\text {inf }}(\bar{\Gamma}), \mu_{\text {sup }}(\bar{\Gamma})\right]$, being evenly distributed on this interval.

(iii) Finally, if the incumbent produces an amount of public good that exceeds $\bar{\Gamma}$, then voters believe that the incumbent is highly competent: $\mu>\mu_{\text {sup }}(\bar{\Gamma})$, being evenly distributed on the interval $\left[\mu_{\text {inf }}(\bar{\Gamma}), 1\right]$.

Given this system of beliefs, the voters' strategy can be rewritten as reelecting the incumbent with an intermediate or high level of competence and not reelecting one with a low level of competence. Note that, in equilibrium, there is partial disclosure of the type of incumbent, in such a way that, even though politicians are identical ex-ante, an incumbent discloses information about his type during his term of office. ${ }^{11}$

It remains to show that this strategy is sequentially rational, given the beliefs, and that the beliefs are consistent with the profile of strategies in the equilibrium path. This result is confirmed in the Appendix. Therefore, the profile of strategies obtained, combined with the system of beliefs described above, yields a perfect Bayesian equilibrium of the game.

\footnotetext{
${ }^{11}$ We thank an anonymous referee for emphasizing this equilibrium property.
} 


\section{Parameterization}

In order to illustrate and better understand the model, we introduce a parameterization for the electoral game using available studies and data on the Brazilian economy for 2004 .

\subsection{Parameter determination}

There are four parameters that should be estimated in the model: value $b$ of the per capita public budget, the maximum diversion of public resources $r_{\max }$, the measure of heterogeneity of candidates' competence $\xi$, and the intertemporal discount factor $\delta$.

For the calculation of public budget, one uses the data from the Brazilian National Treasury Secretariat website, ${ }^{12}$ Table 2. According to this table, the National Treasury expenditures totaled $\mathrm{R} \$ 147.310$ billion, corresponding to $24 \%$ of the Brazilian GDP. The two expenditure categories are earmarked and ordinary expenditures. Parameter $r_{\max }$ does not include earmarked resources. Under ordinary expenses, we have the following subcategories: public labor compensation, social expenditure, social security interest payments, public debt interest payments, social welfare benefits, maintenance and investment, official credit operations, and remaining balance. The latter subcategory does not include any expenditure, i.e., there were no expenditures regarding the remaining balance of other periods in 2004. The analysis of these subcategories led us to consider that maintenance and investment best represents diversion opportunities, totaling $\mathrm{R} \$ 72,266$ billion, corresponding to $4.09 \%$ of GDP. Finally, the IPEADATA webpage presents an estimate for the 2004 per capita GDP, denominated in dollars, based on the mean exchange rate for that year, considering the population of July 1st, $2004 .{ }^{13}$ The corresponding value amounted to US $\$ 3,325.06$. Therefore, the National Treasury's per capita government expenditure corresponded to $b=0.24^{*} 3,325.06=798.02$ dollars in 2004. Furthermore, the per capita amount spent on maintenance and investment totaled $r_{\max }=0.0409^{*} 3,325.06=136.00$ dollars.

According to Cândido Jr. (2001), the productivity of the public sector expenditure in Brazil averages $60 \%$ of private sector expenditure productivity. Given that the characteristic competition of the private sector excludes incompetent administrators from the market, this model assumes that the type of the private administrator is $\mu_{p}=\mu_{\max }=1$, the highest possible competence for the public sector. Thus, the average competence of the public sector, $E[\mu]=11 /(2 \xi)$, satisfies $E[\mu]=0.6 \mu_{\max }$, hence, $\xi=1.25$.

\footnotetext{
${ }^{12}$ http://www.stn.fazenda.gov.br/hp/downloads/resultado/Tabela2.xls.

${ }^{13}$ http://www.ipeadata.gov.br/ipeaweb.dll/ipeadata?12110359.
} 
Finally, most traditional economic models take extremely high values for the discount factor, usually between 0.97 and 0.99 . However, in models involving politicians there seems to be an agreement that the latter discount more the future. ${ }^{14}$ Thus, a value smaller than $\delta=0.9$ was initially used.

Note that, given the difficulty in measuring parameters $\xi$ and $\delta$, a sensitivity analysis of these parameters will also be presented in this paper, with values of $\delta$ ranging from 0.79 and 0.99 .

\subsection{The electoral criterion}

Figure 1 obtains by applying the parameterization to the utilities derived for each case and using version 6.5 of MATLAB. It presents the electoral criterion $\Gamma$ on the abscissa and the voter's expected utility on the ordinate. The voter's optimal choice occurs at $\Gamma^{*}=502.60$, which corresponds to Case 3 with interior solution. In addition, it is interesting to confirm that the utility function is concave for intermediate values of $\Gamma$. The different segments of the curve were denoted by different colors, corresponding respectively to different cases. Case 1 is the green segment further to the left, Case 2 is the subsequent red segment, Case 3 is the blue segment and so on and so forth. The horizontal segments of the figure correspond to extreme situations in which the incumbent will choose the maximum diversion in the first period regardless of his type. This occurs either because the reelection criterion is too lenient (horizontal segment further to the left), in which case the incumbent will always be reelected, or then because the criterion is too strict (segment further to the right), in which case he will never be reelected.

\subsection{Comparative statics}

In this section, we assess the effect of variations in parameters $\delta$ and $\xi$ on reelection criterion $\Gamma$. The following table summarizes the numerical results obtained.

\footnotetext{
${ }^{14}$ See, for instance, a discussion in Rasmusen (1997).
} 


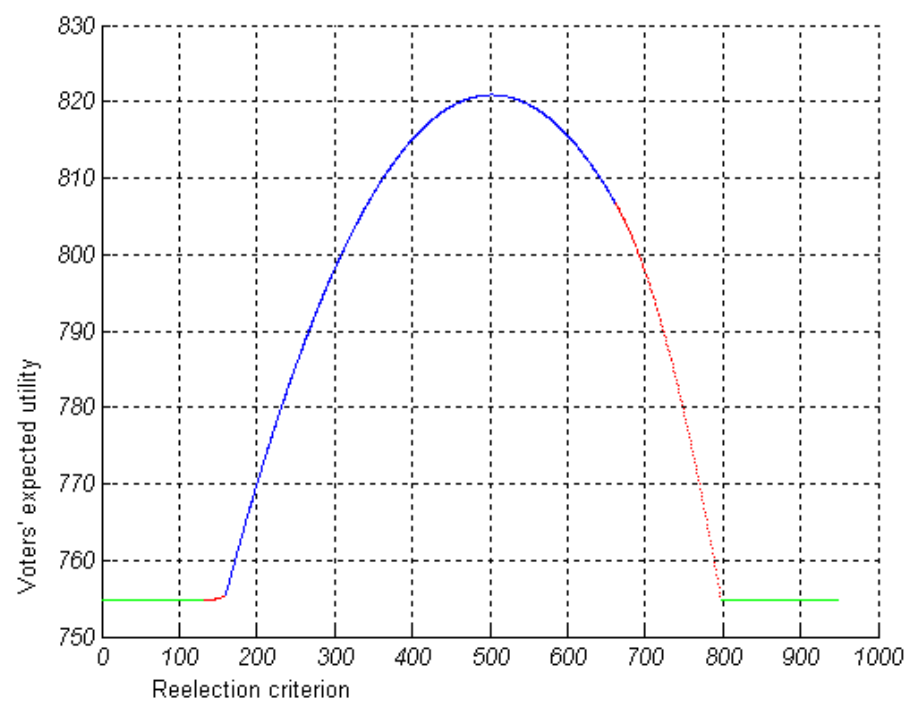

Figure 4

Voters' expected utility as a function of the reelection criterion

The values shown in the table first confirm that the model is robust to wide variations in parameters $\delta$ and $\xi$. Also, the numerical results suggest a monotonic variation of the electoral criterion with these parameters. Let us analyze that behavior.

Table 1

Optimal reelection criterion $\Gamma$ for different intertemporal discount factor values $\delta$ and for competence parameter $\xi$

\begin{tabular}{ccccccc}
\hline$\delta$ & 0.79 & 0.83 & 0.87 & 0.91 & 0.95 & 0.99 \\
$\xi$ & & & & & & \\
\hline 1.1 & 460.05 & 458.55 & 457.55 & 556.55 & 455.55 & 454.55 \\
1.2 & 492.00 & 490.50 & 489.00 & 488.00 & 487.00 & 486.00 \\
1.3 & 518.16 & 517.16 & 516.16 & 515.16 & 514.16 & 513.16 \\
1.4 & 542.01 & 540.51 & 539.01 & 538.01 & 537.01 & 536.01 \\
1.5 & 562.01 & 560.51 & 559.01 & 558.01 & 556.51 & 555.51 \\
1.6 & 579.76 & 578.26 & 576.76 & 575.26 & 574.26 & 573.26 \\
\hline
\end{tabular}


The higher parameter $\xi$, the smaller the difference in competence between different incumbents. Therefore, the higher $\xi$, the less costly it is for voters to replace an incumbent. Thus, voters become more demanding in their reelection criterion as $\xi$ increases.

On the other hand, the higher parameter $\delta$, the more important the future becomes for voters. Therefore, the higher parameter $\delta$, the more costly it will be to replace an incumbent with another one whose competence could be poorer. So, voters become less demanding in their reelection criterion as $\delta$ increases.

\section{Risk Aversion}

The equilibrium found in the previous asymmetric information game is robust since it is a perfect Bayesian equilibrium. However, the game formulation assumes that the voters' utility function is linear in the term that accounts for the utility for the public good. This hypothesis hinders the analysis of the effect of risk aversion on voters' decision. On the other hand, the existence of uncertainty in the model suggests that the attitude of voters with respect to risk may change their electoral decisions. The present section extends the original model in order to explore how voters' optimal choice is affected by their level of risk aversion.

The most natural way of incorporating risk aversion in the behavior of representative voters is by redefining the instantaneous utility function as follows:

$$
w_{t}=y-b+\gamma_{t}^{\theta}
$$

In this new utility, $\theta \in(0,1]$ represents the voter's risk aversion to the consumption of the public good. Therefore, if $\theta=1$ one has the previous model in which voters are risk-neutral while as the values of $\theta$ decrease, risk aversion increases. ${ }^{15}$ For values of $\theta$ greater than 1 voters become risk lovers.

It is important to establish a parallel between the assumption of risk aversion introduced here and the assumption of risk neutrality of the principal in the classic principal-agent models. Indeed, the classic principal-agent models typically consider the principal to be an employer or an investor who, for signing contracts with a large number of employees or investments, can diversify his risk, therefore being regarded as risk-neutral. ${ }^{16}$ This is indeed a simplifying hypothesis that allows solving problems which are usually difficult to be solved explicitly. In the present model, voters play the role of principal but clearly cannot diversify as an employer does, since they elect a single incumbent. Therefore, it is more natural and also important to understand how risk aversion affects electoral behavior.

\footnotetext{
${ }^{15}$ The coefficient of absolute risk aversion of the above function is $(1-\theta) / \gamma_{t}$, which varies from zero when $\theta=1$ (case of risk neutrality) to values close to $1 / \gamma_{t}$ when $\theta$ approaches zero.

${ }^{16}$ See, for instance, Salanié (1997).
} 
Note that the extensive form of the game remains unchanged, as shown in Figure 1, where now the values of $w_{1}$ and $w_{2}$ which appear in the voters' utility functions should be calculated according to Equation (10) in spite of Equation (4).

Despite the new utility function for the voter, the solution procedure by sequential rationality is analogous, and the changes and major complications appear in the solution to the five cases analogous to the previous ones. Given the more complex format of the objective function, it was not possible to find an explicit algebraic solution to the model. Nevertheless, following the same procedure as before, we can easily show that the function generated by the association of the five cases is continuous throughout the real domain. Moreover, one expects the resulting function to remain concave on the relevant interval, at least for values close to $\theta=1$, by continuity.

Our numerical analysis uses MATLAB 6.5, based on the model that was previously parameterized. Table 2 provides the optimal reelection criterion adopted by voters, $\Gamma$, as a function of the risk aversion parameter. The table shows that the more risk-averse voters are, which corresponds to smaller values of $\theta$, the less demanding they will be in terms of their reelection criterion. Then, for example, when $\theta=1$ which corresponds to the case of risk neutrality assessed in the previous section - it will be necessary to produce public goods corresponding to US $\$ 502.60$ per capita for the incumbent to be reelected. However, this level of commandment decreases until it reaches a value of US\$453.40 per capita for the case in which $\theta=0.1$. Suppose that actually drops from 1 to 0.1 ; this would correspond to a loss of electoral control of over US\$50 per capita, a reasonable value given the average income of the Brazilian population, and which corresponds to a loss greater than $10 \%$ of the electoral control.

Therefore, more risk-averse voters tend to be more tolerant of their elected representatives, accepting to reelect them when they produce a small amount of public good. This occurs because the cost of replacing an incumbent is higher for risk-averse voters, due to the uncertainty surrounding the replacement with a new incumbent. This result draws attention to a possible inverse correlation between risk aversion of a society and the interchangeability of political parties in power, a conjecture that deserves further studies. 
Table 2

Optimal reelection criterion $\Gamma$ for different risk aversion parameter values $\theta$

\begin{tabular}{cccccccccc}
\hline$\theta$ & 0.1 & 0.3 & 0.5 & 0.7 & 0.9 & 1.0 & 1.1 & 1.3 & 1.5 \\
\hline$\Gamma$ & 453.60 & 464.60 & 474.60 & 485.60 & 496.60 & 502.60 & 507.60 & 518.60 & 530.60 \\
\hline
\end{tabular}

Figure 5 shows the voters' expected utility when risk aversion parameter $\theta$ assumes value 0.1 , where the reelection criterion decreases from $\Gamma^{*}=502.60$ to 453.40 .

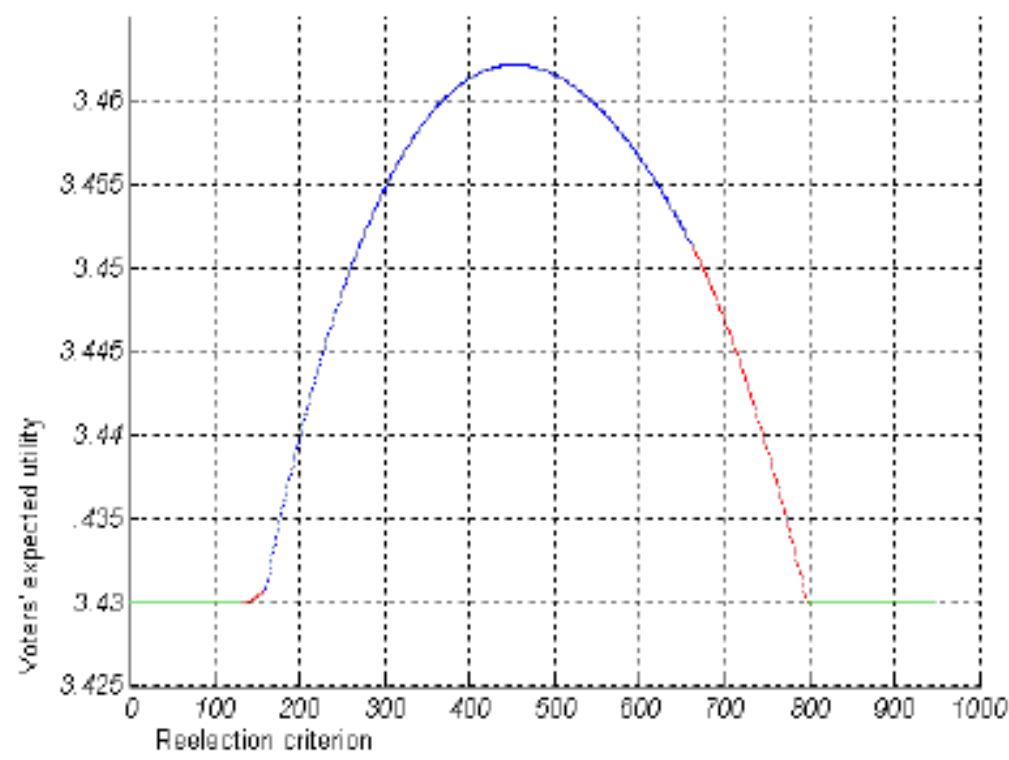

Figure 5

Voters' expected utility with risk aversion parameter 0.1

\section{Limitations and Extensions of the Model}

The present study takes several simplifying hypotheses that must be addressed to better understand the political interaction between voters and their incumbents. $^{17}$

First, since this a model involving a representative voter, the approach disregards all the electoral motivation associated with the so-called redistributive view of politics. ${ }^{18}$ According to that view, the application of public resources affects

\footnotetext{
${ }^{17}$ The authors thank the comments by two anonymous referees who encouraged the discussions introduced in this section.

${ }^{18}$ See Shepsle and Weingast (1995).
} 
different social groups in distinct ways, and what drives the choice of a voter is the allocation of public expenditures to his group. Take for example a childless couple living in a big city. They show little interest in the amount of resources destined to elementary school education, and would rather that these resources be invested in safety and urban infrastructure. Basically, this view regards the politician as a provider of local public goods and each group will vote for the candidate that maximizes public expenditure on the public good that matters to it. An approach like this one would enrich the model, making voters be concerned also with the internal organization of the Legislature, where many of the negotiations involving local public goods are conducted, as carefully modeled in Baron and Ferejohn (1989). However, this modeling would involve a conflict between different groups of voters, taking the focus of the paper away from that which voters have in common, i.e., the concern with reducing the diversion of public resources and choosing more competent politicians. An extension of the present study aimed at adding further heterogeneity without losing the focus on the voters' common interest constitutes a challenge for future research.

Second, it is important to discuss the emphasis the present study places on voters' focus on selecting the most competent candidate. This is a well-established approach in the literature, which was consolidated in Rogoff (1990), which introduces the political budget cycles theory. This approach is very natural when the politician provides each voter with the same amount of public good. If the possibility of a local public good addressed in the previous paragraph is included, then many voters will be willing to relinquish some competence if they can guarantee more resources to their region. An interesting example of this problem is debated in Ferreira and Bugarin $(2006,2007)$, who show that there exist voluntary intergovernmental transfers that are triggered by political identification between mayors and state governors. In that case, voters of a given municipality may prefer to elect a less competent candidate, but who belongs to the same party as the governor, thus ensuring larger transfers from the state government, than to elect a more competent candidate from the opposition party. An extension of the present model including that concern would be extremely productive.

Third, one should question the assumption that society does not perceive the diversion of resources by the incumbent, since there are several institutional mechanisms, both official (e.g.: Courts of Auditors) and unofficial (e.g.: the press), which can disclose signals of diversion to the society. The hypothesis of the model is supported by the fact that these signals tend to give little information in the short run, which is the time interval that matters for a voter's decision. In fact, when such signals become available in the short run, they tend to be used as political campaign tools, which confuse voters about their real information content. Therefore, the present modeling can be seen as an extreme case in which signals are totally uninformative at election time. An extension that includes partially informative signals would affect the representative voter's decision, who would now have his 
reelection strategy contingent on the signal, but one expects that, contingent on this new information, the main messages of the study remain unchanged.

Fourth, the intertemporal issue regarding the incumbent's decision could be added to the model by including public goods with different maturity dates. This approach has already been developed in Rogoff (1990) in which there are public goods of immediate consumption and public goods of future consumption (investments). The authors refer the reader to that paper for a careful discussion about the effect of this friction.

Fifth, the model could be improved with the inclusion of a larger number of periods. If there is a finite number of periods with possibility for reelection, then the model resolution would follow the principle of backward induction used herein and the main results are expected to repeat themselves, with the additional result that being reelected now is less interesting to the incumbent as time goes by, since the number of future periods of permanence in power decreases. So, voters are expected to have greater control over the incumbent by choosing a more demanding reelection rule, in the first periods of the game, and lesser control in the final periods. Note however that if the there are term limits, then one knows beforehand that the politician in his possibly last term in office will divert more resources, which will make voters not reelect an incumbent in his penultimate term in office, which in turn, will hinder the whole strategy of electoral control; in this case, voters will have no other choice but to reelect the most competent politician. In addition, one could consider an infinitely repeated game in which the "incumbent" is a political party with unlimited possibility of reelection and determine its steady state. In this case, the basic message of the current model is expected to persist. If there are reelection restrictions, then the control is lost again and the voters' decision is reduced to trying to choose the most competent candidates. Note that a more careful treatment of competence is necessary in this richer context, since one expects that competence has a dynamic characteristic, differing in each period, but also showing some permanence, as modeled in Rogoff (1990) and in Ferreira and Bugarin (2006, 2007).

Finally, it should be highlighted that the perfect Bayesian equilibrium presented here postulates a pure strategy of voters. It would be possible, however, to explore a mixed strategy in which voters would determine the probability of reelecting the incumbent for each possible realization of production of public good $\Gamma$. Such an extension is left as suggestion for future research.

\section{Conclusion}

The present paper assessed the optimal choice of a voter regarding his decision to keep or replace an elected politician in power. Initially, two factors played a key role in this choice. First, the voter wants to control the incumbent, and he will reelect him only if his performance is satisfactory enough. On the other hand, the voter does not want to be too demanding so as not to reelect a competent 
incumbent, replacing him with a potentially less competent one. Section 2 showed how the voter handles both the moral hazard problem (controlling the incumbent) and the adverse selection problem (keeping a competent incumbent in power), in a model in which voters are risk-neutral.

The analysis evinced the trade-off between adverse incentive (moral hazard) and adverse selection faced by voters. On the one hand, a softer reelection criterion does not allow the worst types to be excluded and allows the most competent incumbents to divert more public resources and to be reelected; however, less competent incumbents divert fewer resources in order to be reelected. On the other hand, a more demanding reelection criterion reduces diversions in the first period for some more competent incumbents at the cost of not reelecting other reasonably competent incumbents; the incumbents who will not be reelected will choose to divert more resources. In equilibrium, voters will choose an intermediate reelection criterion which will imply a partial control of corruption and partial selection of the competent incumbent. The study provided evidence that the higher the dispersion of competence in the political universe, i.e., the more heterogeneous politicians are in terms of administrative capacities, the less demanding the reelection criteria will be. In addition, the greater importance voters attach to the future, the less demanding they will be when reelecting a politician.

Considering that voters do not know about the incumbent's competence, and since this affects their performance as providers of public goods to the society, a third potentially important factor was investigated regarding voters' decision, i.e., risk aversion. A numerical study revealed smaller control of voters over the incumbent as they become more risk averse. This is an important new result of this paper, suggesting there will be higher political stability in countries in which populations are more risk averse, with the same party being reelected more frequently. On the other hand, the study also suggests higher political instability in countries with a less risk-averse population, with large interchangeability of parties in power. An empirical study aimed at testing these assumptions is suggested for future research.

\section{References}

Alesina, A. \& Rosenthal, H. (1989). Partisan cycles in congressional elections and the macroeconomy. American Political Science Review, 83:373-398.

Alesina, A. \& Rosenthal, H. (1995). Partisan Politics, Divided Government and the Economy. Cambridge University Press.

Alesina, A. \& Rosenthal, H. (1996). A theory of divided government. Econometrica, 64:1311-1341.

Baron, D. \& Ferejohn, J. (1989). Bargaining in legislatures. American Political Science Review, 89:1181-1206. 
Barro, R. (1973). The control of politicians: An economic model. Public Choice, 14:19-42.

Bugarin, M. (1999). Vote splitting as insurance against uncertainty. Public Choice, 98:153-169.

Bugarin, M. (2002). Vote splitting, reelection and electoral control: Towards a unified model. Social Choice and Welfare, 20:137-154.

Cândido Jr., J. O. (2001). Os gastos públicos no Brasil são produtivos? Texto para Discussão IPEA 781.

Chari, V., Jones, L., \& Marimon, R. (1997). The economics of split-ticket voting in representative democracies. American Economic Review, 87:957-976.

Downs, A. (1957). An Economic Theory of Democracy. Harper and Row, New York.

Ferejohn, J. (1986). Incumbent performance and electoral control. Public Choice, $50: 5-26$

Ferreira, I. \& Bugarin, M. (2006). Political budget cycles in a fiscal federation: The effect of partisan voluntary transfers. Working Paper. http://bugarin.ibmecsp.edu.br/papers/PoliticalBudgetCyclesFiscalFederation 20051209.pdf.

Ferreira, I. \& Bugarin, M. (2007). Transferências voluntárias e ciclo políticoorçamentário no federalismo fiscal brasileiro. Revista Brasileira de Economia, 61(3):271-300.

Fiorina, M. P. (1988). The Reagan years: Turning to toward the right of groping toward the middle? In Kornberg, A. \& Mishler, W., editors, The Resurgence of Conservatism in Anglo-American Democracies. Duke University Press, Durham, NC.

Fiorina, M. P. (1992). An era of divided government. Political Science Quarterly, $107: 387-410$

Fiorina, M. P. (1996). Divided Government. Allyn and Bacon, Boston, second edition.

Holmström, B. (1982). Managerial incentive problems - A dynamic perspective. Review of Economic Studies, 66:169-82. 1999.

Kerr, W. A. (1944). A quantitative study of political behavior. Journal of Social Psychology, 19:273-81. 
Kramer, G. H. (1971). Short term fluctuations in U.S. voting behavior, 1896-1964. American Political Science Review, 65:131-43.

Madison, J. (1788). The federalist. Independent Journal, 39. http://www.constitution.org/fed/federa39.htm.

Nordhaus, W. (1975). The political business cycle. Review of Economic studies, 42:169-90.

Persson, T. \& Tabellini, G. (2000). Political Economics - Explaining Economic Policy. The MIT Press.

Rasmusen, E. (1997). A theory of trustees and other thoughts. Public Debt and its Finance in a Model of a Macroeconomic Policy Game. Papers presented at a workshop held in Antalya, Turkey on October 10-11, 1997, edited by Tahire Akder.

Rogoff, K. (1990). Equilibrium political budget cycles. American Economic Review, 80:21-36.

Rogoff, K. \& Sibert, A. (1988). Elections and macroeconomic policy cycles. Review of Economic Studies, 55:1-16.

Salanié, B. (1997). The Economics of Contracts. MIT Press, Cambridge.

Shepsle, K. \& Weingast, B. (1995). Positive Theories of Congressional Institutions. The University of Michigan Press, Ann Arbor. 


\section{Appendix}

\section{Electoral Control Potential}

Suppose that the incumbent in period 1 is of the type $\mu \in\left[\mu_{\text {inf }}, \mu_{\text {sup }}\right)$ and that voters adopt reelection strategy $(7)$, i.e., the incumbent will be reelected if he produces a minimum amount $\Gamma$ of public good. Then, the incumbent has the following choice. If he diverts the maximum amount possible but still produces $\Gamma$, his diversion choice will have to be $r_{1}=b-\frac{\Gamma}{\mu}$, he/she will be reelected, will divert $r_{\max }$ in the second period and his utility in both periods will be $b-\frac{\Gamma}{\mu}+\delta\left(r_{\max }+R\right)$. On the other hand, if he diverts $r_{\max }>r_{1}$ in the first period, he/she will not be reelected and his utility will simply be $r_{\max }$. The incumbent will decide to divert less in the first period if and only if $b-\frac{\Gamma}{\mu}+\delta\left(r_{\max }+R\right) \geq r_{\max }$. Note that the incumbent with the highest incentive to choose the maximum diversion is the least competent incumbent, of the type $\mu=\mu_{\text {inf }}=\frac{\Gamma}{b}$. Therefore, if this incumbent prefers not to divert $r_{\max }$, then no other incumbent of the type $\mu \in\left[\mu_{\text {inf }}, \mu_{\text {sup }}\right)$ will do it. This will occur if and only if $b-\frac{\Gamma}{\mu_{\text {inf }}}+\delta\left(r_{\max }+R\right) \geq r_{\max } \Leftrightarrow \delta\left(r_{\max }+R\right) \geq$ $r_{\max } \Leftrightarrow R \geq\left(\frac{1-\delta}{\delta}\right) r_{\max }$, which corresponds to condition (6).

\section{The Explicit Form of the Objective Functions}

The explicit form of the objective function for Cases 1 and 5 was presented in the text. The forms corresponding to Cases 2, 3 and 4 are calculated in what follows.

Case 2:

$$
\begin{aligned}
& \int_{1-\frac{1}{\xi}}^{\mu_{\text {sup }}}\left[\Gamma+\delta \mu\left(b-r_{\max }\right)\right] f(\mu) d \mu+\int_{\mu_{\text {sup }}}^{1}(1+\delta) \mu\left(b-r_{\max }\right) f(\mu) d \mu \\
= & \xi \Gamma\left[\frac{\Gamma}{b-r_{\max }}-1+\frac{1}{\xi}\right]+\xi \delta \frac{b-r_{\max }}{2}\left[\left(\frac{\Gamma}{b-r_{\max }}\right)^{2}-\left(1-\frac{1}{\xi}\right)^{2}\right] \\
+ & \xi(1+\delta) \frac{b-r_{\max }}{2}\left[1-\left(\frac{\Gamma}{b-r_{\max }}\right)^{2}\right]
\end{aligned}
$$


Case 3:

$$
\begin{aligned}
& \int_{1-\frac{1}{\xi}}^{\mu_{\mathrm{inf}}}\left[\mu\left(b-r_{\max }\right)+\delta E[\mu]\left(b-r_{\max }\right)\right] f(\mu) d \mu \\
+ & \int_{\mu_{\mathrm{inf}}}^{\mu_{\mathrm{sup}}}\left[\Gamma+\delta \mu\left(b-r_{\max }\right)\right] f(\mu) d \mu+\int_{\mu_{\mathrm{sup}}}^{1}(1+\delta) \mu\left(b-r_{\max }\right) f(\mu) d \mu \\
= & \xi \frac{b-r_{\max }}{2}\left[\left(\frac{\Gamma}{b}\right)^{2}-\left(1-\frac{1}{\xi}\right)^{2}\right] \\
+ & \xi \delta\left(b-r_{\max }\right)\left[1-\frac{1}{2 \xi}\right]\left[\frac{\Gamma}{b}-1+\frac{1}{\xi}\right] \\
+ & \left.\xi \Gamma^{2} \frac{r}{b\left(b-r_{\max }\right.}\right) \xi \frac{1}{2}\left[\left(\frac{1}{b-r_{\max }}\right)^{2}-\left(\frac{1}{b}\right)^{2}\right] \\
+ & \xi(1+\delta) \frac{b-r_{\max }}{2}\left[1-\left(\frac{\Gamma}{b-r_{\max }}\right)^{2}\right]
\end{aligned}
$$

Case 4:

$$
\begin{aligned}
& \int_{1-\frac{1}{\xi}}^{\mu_{\mathrm{inf}}}\left[\mu\left(b-r_{\max }\right)+\delta E[\mu]\left(b-r_{\max }\right)\right] f(\mu) d \mu \\
+ & \int_{\mu_{\mathrm{inf}}}^{1}\left[\Gamma+\delta \mu\left(b-r_{\max }\right)\right] f(\mu) d \mu=\xi \frac{b-r_{\max }}{2}\left[\left(\frac{\Gamma}{b}\right)^{2}-\left(1-\frac{1}{\xi}\right)^{2}\right] \\
+ & \xi \delta\left(b-r_{\max }\right)\left[1-\frac{1}{2 \xi}\right]\left[\frac{\Gamma}{b}-1+\frac{1}{\xi}\right]+\xi \Gamma\left[1-\frac{\Gamma}{b}\right] \\
+ & \xi \delta \frac{b-r_{\max }}{2}\left[1-\left(\frac{\Gamma}{b-r_{\max }}\right)^{2}\right]
\end{aligned}
$$




\section{Detailed Analysis of Case 2: Partially Demanding Voters}

Suppose that $\mu_{\text {sup }}>1-\frac{1}{\xi}$ and $\mu_{\text {inf }} \leq 1-\frac{1}{\xi}$, which corresponds to $\left(1-\frac{1}{\xi}\right)(b-$ $\left.r_{\max }\right)<\Gamma \leq\left(1-\frac{1}{\xi}\right) b$.

Figure A.1 shows the positions of $\mu_{\mathrm{inf}}$ and of $\mu_{\mathrm{sup}}$ in relation to the support of $\mu$ and presents the optimal choice of the incumbent, $r_{1}$, according to his competence. ${ }^{19}$

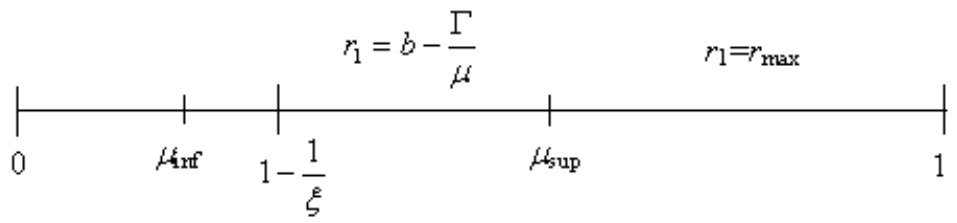

Figure A.1

Case 2: Partially demanding voters

Note that in this case the voter is a little more demanding, in such a way that the reelection criterion allows separating the incumbents into two classes. First, very competent incumbents for whom $\mu \in\left[\mu_{\text {sup }}, 1\right]$ can divert as many resources as possible and still be reelected. Therefore, for these incumbents $r_{1}=r_{\max }$.

On the other hand, less competent incumbents for whom $\mu \in\left[1-\frac{1}{\xi}, \mu_{\text {sup }}\right]$ will have to give up on some diversion in order to be reelected. According to condition (6), they will choose $r_{1}=b-\frac{\Gamma}{\mu}$.

The expected utility of voters in this case can be expressed as:

$$
\int_{1-\frac{1}{\xi}}^{\mu_{\text {sup }}}\left[\Gamma+\delta \mu\left(b-r_{\max }\right)\right] f(\mu) d \mu+\int_{\mu_{\text {sup }}}^{1}(1+\delta) \mu\left(b-r_{\max }\right) f(\mu) d \mu
$$

The first term of the function above represents the case in which the incumbent meets the reelection criterion by producing $\Gamma$ and is reelected. The second term represents the situation in which the incumbent is very competent, diverts as many resources as possible and is reelected.

\footnotetext{
${ }^{19}$ Note that: $\mu_{\text {sup }}<1$ if and only if $\Gamma<\left(b-r_{\max }\right)$. Since $b>2 r_{\max }>r_{\max } \xi$, then $\left(1-\frac{1}{\xi}\right) b<b-r_{\max }$. Therefore, as $\Gamma \leq\left(1-\frac{1}{\xi}\right) b$, we indeed have $\mu_{\text {sup }}<1$. 
Suppose that voters consider choosing reelection criterion $\Gamma$ for the interval considered in this case, i.e., $\Gamma \in\left(\left(1-\frac{1}{\xi}\right)\left(b-r_{\max }\right),\left(1-\frac{1}{\xi}\right) b\right]$. Then, voters will solve the following problem:

$$
\left\{\begin{array}{l}
\max _{\Gamma} \int_{1-\frac{1}{\xi}}^{\mu_{\text {sup }}}\left[\Gamma+\delta \mu\left(b-r_{\max }\right)\right] f(\mu) d \mu+\int_{\mu_{\text {sup }}}^{1}(1+\delta) \mu\left(b-r_{\max }\right) f(\mu) d \mu \\
\text { s.a: }\left(1-\frac{1}{\xi}\right)\left(b-r_{\max }\right)<\Gamma \leq\left(1-\frac{1}{\xi}\right) b
\end{array}\right.
$$

By integrating the objective function, one obtains an upward parabola that reaches its minimum at $\Gamma=\left(1-\frac{1}{\xi}\right)\left(b-r_{\max }\right)$. Therefore, the objective function is strictly increasing at $\Gamma$ on the interval considered, such that voters will choose the highest $\Gamma$ possible, $\Gamma=\left(1-\frac{1}{\xi}\right) b$.

Note that on this interval of $\Gamma$ values, voters focus their concerns entirely on electoral control (moral hazard), setting the selection problem aside (adverse selection). This occurs because on this interval of $\Gamma$ values voters do not risk inducing an incumbent to choose the maximum diversion for not meeting the reelection criterion: all types of incumbents can meet that criterion. The next figure shows the optimal choice of $\Gamma$ in this case, with the corresponding values of $\mu_{\mathrm{inf}}, \mu_{\mathrm{sup}}$, as well as the corresponding choices of the incumbent according to his type.

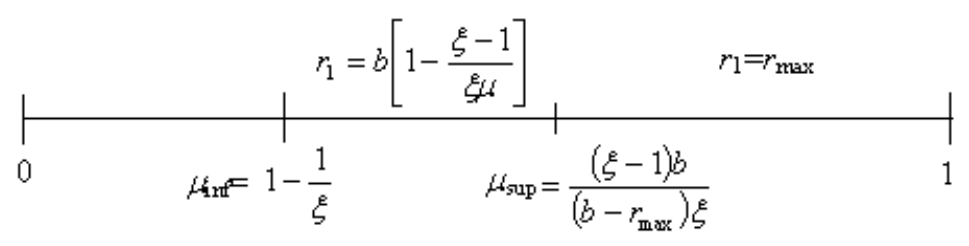

Figure A.2

Case 2: Optimal choices on the interval $\Gamma \in\left(\left(1-\frac{1}{\varepsilon}\right)\left(b-r_{\max }\right),\left(1-\frac{1}{\varepsilon}\right) b\right]$ 


\section{Additional Calculations Regarding Case 3}

From the second-order conditions of voter's problem (11) we obtain that:

$$
\frac{\partial^{2} \cdot}{\partial \Gamma^{2}}=\frac{\left(b-r_{\max }\right)^{2}(1-\delta)-\left(b-2 r_{\max }\right) b}{b^{2}\left(b-r_{\max }\right)}
$$

The denominator of this derivative is positive. Therefore, it will be negative if and only if its numerator is negative. But, $\left(b-r_{\max }\right)^{2}(1-\delta)-\left(b-2 r_{\max }\right) b=r_{\max }^{2}$. So, the second derivative will be negative if and only if $\delta>\frac{r_{\max }^{2}}{\left(b-r_{\max }\right)^{2}}=\delta_{1}$.

Note that, since $b>2 r_{\max }$, then $\delta_{1}=\frac{r_{\max }^{2}}{\left(b-r_{\max }\right)^{2}}<\frac{r_{\max }^{2}}{\left(2 r_{\max }-r_{\max }\right)^{2}}=1$. Therefore, the utility function of voters will be concave in Case 3 if and only if $\delta>\frac{r_{\max }^{2}}{\left(b-r_{\max }\right)^{2}}$.

If the representative voter's problem were unrestricted, the maximum would be given at:

$$
\Gamma^{*}=\left(1-\frac{1}{2 \xi}\right) \frac{\delta\left(b-r_{\max }\right)^{2} b}{b\left(b-2 r_{\max }\right)-(1-\delta)\left(b-r_{\max }\right)^{2}}
$$

Note that $\Gamma^{*}=\left(1-\frac{1}{\xi}\right) b \Leftrightarrow\left(1-\frac{1}{2 \xi}\right) \frac{\delta\left(b-r_{\max }\right)^{2} b}{b\left(b-2 r_{\max }\right)-(1-\delta)\left(b-r_{\max }\right)^{2}}>\left(1-\frac{1}{\xi}\right) b$.

But this is equivalent to:

$$
\left(1-\frac{1}{2 \xi}\right) \delta\left(b-r_{\max }\right)^{2}>\left(1-\frac{1}{\xi}\right)\left[b\left(b-2 r_{\max }\right)-(1-\delta)\left(b-r_{\max }\right)^{2}\right]
$$

Since $\xi>1$, the inequality above will be satisfied if:

$$
\delta\left(b-r_{\max }\right)^{2}>b\left(b-2 r_{\max }\right)-(1-\delta)\left(b-r_{\max }\right)^{2}
$$

But the inequality above is equivalent to: $\left(b-r_{\max }\right)^{2}>b^{2}-2 b r_{\max }$, which is always true. Therefore, $\Gamma^{*}>\left(1-\frac{1}{\xi}\right) b$.

Now consider $\Gamma^{*}<b-r_{\max } \Leftrightarrow\left(1-\frac{1}{2 \xi}\right) \frac{\delta\left(b-r_{\max }\right)^{2} b}{b\left(b-2 r_{\max }\right)-(1-\delta)\left(b-r_{\max }\right)^{2}}<b-r_{\max }$.

The inequality above is equivalent to: $\left(1-\frac{1}{2 \xi}\right) \delta\left(b-r_{\max }\right) b<\delta\left(b-r_{\max }\right)^{2}-$ $r_{\max }^{2}$, which can also be rewritten as: $r_{\max }^{2}<\delta\left(\frac{b}{2 \xi}-r_{\max }\right)\left(b-r_{\max }\right)$ which, in turn, is exactly condition (5). Therefore, condition (5) warrants that $\Gamma^{*}$ is within the open interval $\left(\left(1-\frac{1}{\xi}\right) b, b-r_{\max }\right)$. 


\section{Detailed Analysis of Case 4: Very Demanding Voters}

In this case, we will be dealing with the hypothesis that $1-\frac{1}{\xi} \leq \mu_{\text {inf }}<1$ and $\mu_{\text {sup }}>1$, i.e., $b-r_{\max } \leq \Gamma<b$. Figure A.3 shows this case, in which the voter is even more demanding, such that no type of incumbent, no matter how competent he is, will meet the reelection criterion if he diverts a high amount of resources during his first period. This is the situation in which only more competent incumbents are reelected (selection) and, besides, all reelected incumbents are submitted to a certain type of electoral control (incentive). Nevertheless, there is a large number of incumbents (those with competence $\mu \leq \mu_{\mathrm{inf}}$ ) who are capable of meeting the reelection criterion and therefore will divert as many resources as possible $\left(r_{\max }\right)$, without any electoral control over them by voters.

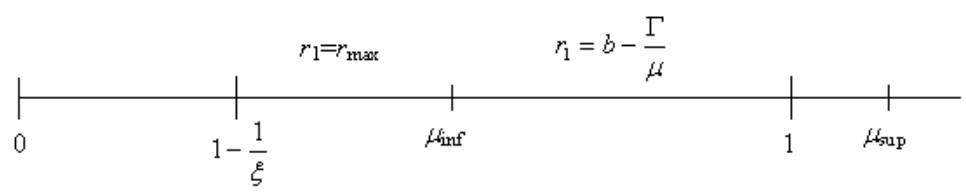

Figure A.3

Case 4: Very demanding voters

The corresponding problem of the voters is now:

$$
\left\{\begin{array}{l}
\max _{\Gamma} \int_{1-\frac{1}{\xi}}^{\mu_{\text {sup }}}\left[\mu\left(b-r_{\max }\right)+\delta E[\mu]\left(b-r_{\max }\right)\right] f(\mu) d \mu \\
+\int_{\mu_{\text {inf }}}^{1}\left[\Gamma+\delta \mu\left(b-r_{\max }\right)\right] f(\mu) d \mu \\
\text { s. } a: b-r_{\max } \leq \Gamma<b
\end{array}\right.
$$

By initially calculating the second derivative of the objective function we obtain the following expression:

$$
\frac{\partial^{2} \cdot\left(b-r_{\max }\right)-2 b-\gamma\left(b-r_{\max }\right)}{\partial \Gamma^{2}}
$$

This derivative will be negative if and only if $\left(b-r_{\max }\right)-2 b-\delta\left(b-r_{\max }\right)=$ $-b-r_{\max }-\delta\left(b-r_{\max }\right)<0$, which is always true. Therefore, the function is strictly concave.

By ignoring the restrictions related to the domain of variable $\Gamma$, we obtain the following first-order condition:

$$
\Gamma^{* *}=\frac{\delta\left(1-\frac{1}{2 \xi}\right) b\left(b-r_{\max }\right)+b^{2}}{2 b-(1-\delta)\left(b-r_{\max }\right)}
$$


Note that $\Gamma^{* *}<b \Leftrightarrow \delta\left(1-\frac{1}{2 \xi}\right)\left(b-r_{\max }\right)+b<2 b-(1-\delta)\left(b-r_{\max }\right)$. But the expression above is equivalent to $\left(1-\frac{\delta}{2 \xi}\right)\left(b-r_{\max }\right)<b$, which is always true. Therefore, $\Gamma^{* *}<b$.

Moreover

$\Gamma^{* *}<b-r_{\max } \Leftrightarrow \delta\left(1-\frac{1}{2 \xi}\right)\left(b-r_{\max }\right) b+b^{2}<2 b\left(b-r_{\max }\right)-(1-\delta)\left(b-r_{\max }\right)^{2}$

The inequality can be rewritten as: $r_{\max }^{2}<\delta\left(\frac{b}{2 \xi}-r_{\max }\right)\left(b-r_{\max }\right)$ which, in turn, is condition (5). Therefore, condition (5) warrants that $\Gamma^{* *}$ is on the left-hand side of interval $\left.b-r_{\max }, b\right)$. But then as the expected utility function of voters in Case 4 is concave and its maximum is on the left side of $b-r_{\max }$, the function is strictly decreasing on the interval corresponding to Case $4,\left(b-r_{\max }, b\right)$.

\section{Continuity of the Voters' Global Utility Function}

To verify whether the voters' utility function is continuous, take the limits when $\Gamma$ approaches the extrema of the intervals in each case and compare them. As an illustrative example, consider the continuity of the function when one goes from Case 1 to Case 2. By taking the limit at the coinciding extrema and recalling that $\mu_{\text {sup }}=\frac{\Gamma}{b-r_{\max }}$ we have, on the one hand that:

$$
\lim _{\Gamma \rightarrow\left(b-r_{\max }\right)\left(1-\frac{1}{\xi}\right)^{-}} \int_{1-\frac{1}{\xi}}^{1}(1+\delta)\left(b-r_{\max }\right) f(\mu) d \mu=\int_{1-\frac{1}{\xi}}^{1}(1+\delta)\left(b-r_{\max }\right) f(\mu) d \mu
$$

And on the other hand that,

$$
\begin{aligned}
& \lim _{\Gamma \rightarrow\left(b-r_{\max }\right)\left(1-\frac{1}{\xi}\right)^{+}} \int_{1-\frac{1}{\xi}}^{\mu_{\text {sup }}}\left[\Gamma+\delta \mu\left(b-r_{\max }\right)\right] f(\mu) \\
+ & \int_{1-\frac{1}{\xi}}^{1}(1+\delta) \mu\left(b-r_{\max }\right) f(\mu) d \mu \\
= & \int_{1-\frac{1}{\xi}}^{1-\frac{1}{\xi}}\left[\Gamma+\delta \mu\left(b-r_{\max }\right)\right] f(\mu)+\int_{1-\frac{1}{\xi}}^{1}(1+\delta) \mu\left(b-r_{\max }\right) f(\mu) d \mu \\
= & \int_{1-\frac{1}{\xi}}^{1}(1+\delta) \mu\left(b-r_{\max }\right) f(\mu) d \mu
\end{aligned}
$$




\section{Perfect Bayesian Equilibrium}

We will see that the profile of strategies coupled with the system of beliefs defined in the text corresponds to a perfect Bayesian equilibrium. To do that, let us consider three cases regarding possible equilibrium paths.

Case 1. Voters observe that the production of public good is less than $\Gamma$.

Then, given the profile of strategies, voters conclude that the competence of incumbent, $\mu_{1}$, is such that $\mu_{1}<\mu_{\mathrm{inf}}(\bar{\Gamma})$. As competence $\mu$ is uniformly distributed on $\left[1-\frac{1}{\xi}, 1\right]$, then Bayesian updating leads to the conclusion that $\mu_{1}$ is uniformly distributed on $\left[1-\frac{1}{\xi}, \mu_{\mathrm{inf}}(\bar{\Gamma})\right]$. Therefore the expected competence of this incumbent is $E\left[\mu_{1}\right]=\frac{1}{2}\left(\mu_{\inf }(\bar{\Gamma})+\left(1-\frac{1}{\xi}\right)\right)<\frac{1}{2}\left(1+\left(1-\frac{1}{\xi}\right)\right)=1-\frac{1}{2 \xi}=E[\mu]$. So, voters' choice not to reelect the incumbent is sequentially rational, given their beliefs.

Case 2. Voters observe that the production of public good is equal to $(\bar{\Gamma})$.

Then, given the profile of strategies, voters conclude that the competence of incumbent, $\mu_{1}$, is such that $\mu_{1} \in\left[\mu_{\mathrm{inf}}(\bar{\Gamma}), \mu_{\text {sup }}(\bar{\Gamma})\right]$. As competence $\mu$ is uniformly distributed on $\left[1-\frac{1}{\xi}, 1\right]$, then Bayesian updating leads to the conclusion that $\mu_{1}$ is uniformly distributed on $\left[1-\frac{1}{\xi}, 1\right]$. Therefore the expected competence of this incumbent is $E\left[\mu_{1}\right]=\frac{1}{2}\left(\mu_{\mathrm{inf}}(\bar{\Gamma})+\mu_{\mathrm{sup}}(\bar{\Gamma})\right)=\frac{\bar{\Gamma}}{2} \frac{2 b-r_{\max }}{2 b\left(b-r_{\max }\right.}=$ $\left(1-\frac{1}{2 \xi}\right) \frac{1}{2} \frac{\delta\left(b-r_{\max }\right)\left(2 b-r_{\max }\right)}{b\left(b-2 r_{\max }\right)-(1-\delta)\left(b-r_{\max }\right)^{2}}$.

But $E[\mu]=1-\frac{1}{2 \xi}$. Therefore, $E\left[\mu_{1}\right]>E[\mu]$ if and only if, $\frac{1}{2}$ $\frac{\delta\left(b-r_{\max }\right)\left(2 b-r_{\max }\right)}{b\left(b-2 r_{\max }\right)-(1-\delta)\left(b-r_{\max }\right)^{2}}>1 \Leftrightarrow \delta\left(b-r_{\max }\right)\left(2 b-r_{\max }\right)>2 b\left(b-2 r_{\max }\right)-2(1-$ $\delta)\left(b-r_{\max }\right)^{2}$.

But the above condition is equivalent to $2 b>(2-\delta)\left(b-r_{\max }\right)$, which is always true, since $2>2-\delta$ and $b>b-r_{\max }$ and all terms are positive.

Therefore, sequential rationality requires that voters reelect the incumbent in this case.

Case 3. Voters observe that the production of public good is greater than $\bar{\Gamma}$.

Then, given the profile of strategies, voters conclude that the competence of incumbent, $\mu_{1}$, is such that $\mu_{1}>\mu_{\text {sup }}(\bar{\Gamma})$. As competence $\mu$ is uniformly distributed on $\left[1-\frac{1}{\xi}, 1\right]$, then the Bayesian updating leads to the conclusion that $\mu_{1}$ is uniformly distributed on $\left[\mu_{\text {sup }}(\bar{\Gamma}), 1\right]$. Then the expected competence of this 
incumbent is $E\left[\mu_{1}\right]=\frac{1}{2}\left(1+\mu_{\text {sup }}\right)>\frac{1}{2}\left(1+\left(1-\frac{1}{\xi}\right)\right)=1-\frac{1}{2 \xi}=E[\mu]$. Therefore, the voters' choice to reelect the incumbent is sequentially rational, given their beliefs. 